\title{
ASSESSING LEVEL OF PREPAREDNESS OF VALI ASR HOSPITAL OF DAREHSHAHR CITY AGAINST DISASTERS IN 2017
}

\author{
Hamid Taghinejad ${ }^{1}$, Mosayeb Mozafari ${ }^{1}$, Ali Khorshidi², Vahid Delshad ${ }^{3}$, Jalil Abbasi ${ }^{4 *}$ \\ ${ }^{l}$ Department of Nursing, Faculty of Nursing and Midwifery, Ilam University of Medical Sciences, Ilam, Iran; \\ ${ }^{2}$ Department of Epidemiology, Faculty of Medicine, Ilam University of Medical Sciences, Ilam, IR Iran; \\ ${ }^{3}$ Health in Emergency and Disaster Research center, University of Social Welfare and Rehabilitation Sciences, \\ Tehran Iran; \\ ${ }^{4 *}$ Department of Nursing, Ilam University of Medical Sciences, Ilam, Iran; \\ *Corresponding author: Jalil Abbasi, email: jali10918@yahoo.com; \\ Hamid2005mordad@yahoo.com; mozafaric@yahoo.com; khorshidi-a@ medilam.ac.ir; delshad.vahid@ gmail.com;
}

Received May, 2018; Accepted June, 2018; Published July, 2018;

DOI: https://doi.org/10.31407/ijees8415

UOI license: http://u-o-i.org/1.01/ijees/46950646

\begin{abstract}
Introduction: Not all hospitals in Iran have necessity preparation to cope with and reduce financial and moral losses from natural disasters and disaster-prone victims in the country. Evidence suggests that hospitals in Iran are not well prepared to deal with disasters. The aim of this study was to assess the readiness of Valiasr Hospital properness for disasters and disaster-prone events in Darehshahr city. Method: Descriptive cross-sectional study was conducted in Valiasr Hospital, Darehshahr city in 2017. National Health Assessment Tool for assessing hospitals and health centers readiness for accidents and disasters was used to collect data for this study. Data collected were analyzed with SPSS version 18. Results: scores of 9 components: Command and Control11(61.10\%), Communication 10(37.04\%), Safety and Security 17(51.52\%), Triage 16(53.30\%), Surge Capacity 13(33.30\%), Continuity of Essential services 11(45.83\%), Human Resources 25(55.56\%), Logistics Management and Supply 17(56.67\%), and Post Disaster Recovery 12(44.40\%) were assessed. In general, average readiness of Valiasr hospital for natural disasters and disaster-prone events was $48.35 \%$. Conclusion: our result indicated that Valiasr's Hospital was only moderately prepared for natural disasters at Command and Control component. However, with the others eight component the hospital was not prepared enough to respond appropriately in crisis situations. Even though the city has been designated as disaster-prone zone, the results obtained shown hospitals lack of preparedness for disaster emergencies. Therefore, more planning and attention in this field is necessary.
\end{abstract}

Keywords: Disasters incidents, Hospital preparedness, DarehShahr 